\title{
IMPLEMENTASI DISCRETE WAVELET TRANSFORM (DWT) DAN SINGULAR VALUE DECOMPOSITION (SVD) PADA IMAGE WATERMARKING
}

\section{IMPLEMENTATION DISCRETE WAVELET TRANSFORM (DWT) AND SINGULAR VALUE DECOMPOSITION (SVD) ON IMAGE WATERMARKING}

\author{
Maretha Ruswiansari ${ }^{1}$, Atik Novianti $^{2}$, Wirawan $^{3}$ \\ ${ }^{1}$ Teknik Informatika, Institut Teknologi Adhi Tama Surabaya \\ ${ }^{2}$ D3 Teknik Telekomunikasi, Telkom University \\ ${ }^{3}$ Teknik Elektro, Institut Teknologi Sepuluh Nopember \\ 1․ㅡaretharuswiansari@itats.ac.id ${ }^{2}{ }^{2}$ atiknovianti@telkomuniversity.ac.id ${ }^{3}{ }^{3}$ irawan@ee.its.ac.id
}

\begin{abstract}
Abstrak
Keaslian informasi dalam berbagai bentuk dan media tidak lagi terjaga karena setiap orang dapat mengubah dan memodifikasinya untuk kemudian disebarkan kembali. Tanda air (watermarking) dapat diartikan sebagai suatu teknik penyisipan dan atau penyembunyian informasi yang bersifat rahasia pada suatu data lainnya untuk "ditumpangi" (kadang disebut dengan host data), tetapi orang lain tidak menyadari adanya kehadiran data tambahan pada data host-nya (istilah host digunakan untuk data atau sinyal digital yang disisipi), sehingga seolah-olah tidak ada perbedaan berarti antara data host sebelum dan sesudah proses watermarking. Pada penelitian ini dilakukan simulasi algoritma watermarking dengan menyisipkan citra watermark ke citra asli menggunakan Discrete Wavelet Transform (DWT) dan Singular Value Decomposition (SVD). Penelitian ini menggunakan citra host berwarna sehingga perlu dilakukan proses konversi citra RGB menjadi komponen $\mathrm{Y}, \mathrm{Cb}$, dan $C r$. Metode DWT-SVD lebih tahan terhadap attack dibandingkan dengan metode DWT. Proses penyisipan watermark dengan Arnold transform menghasilkan PSNR lebih tinggi dibandingkan tanpa Arnold transform, dimana dengan Arnold transform PSNR $=85.7959 \mathrm{~dB}$, dan tanpa Arnold transform PSNR $=85.3901 \mathrm{~dB}$. Semakin rendah PSNR maka semakin tinggi nilai similarity factor (SF) dan semakin jelas watermark-nya.
\end{abstract}

Kata kunci : citra digital, watermarking, DWT, SVD

\begin{abstract}
Authenticity of information in various forms and media are no longer maintained because everyone can change and modify it for later redistributable. Watermarking can be defined as a technique of inserting and hiding or confidential information on an other data for "carrying" (sometimes called the host data), but others are not aware of the presence of additional data on the data its host (the term host is used for data or digital signals inserted), so it seems there is no significant difference between the data host before and after watermarking process. This research will be carried out by inserting the watermarking algorithm simulation image watermark to the original image using the Discrete Wavelet Transform (DWT) and Singular Value Decomposition (SVD). This study used the image of stained host so we need a RGB image conversion process into components $\mathrm{Y}, \mathrm{Cb}$, and Cr. DWT-SVD method is more resistant to attack than the DWT method. The process of embedding with Arnold transform produces higher PSNR than without Arnold transform, where
\end{abstract}


the Arnold transform PSNR $=85.7959 \mathrm{~dB}$, and without Arnold transform PSNR $=85.3901 \mathrm{~dB}$. The lower the value, the higher PSNR similarity factor (SF) and its increasingly clear watermark.

\section{Keywords : digital image, watermarking, DWT, SVD}

\section{PENDAHULUAN}

Pesatnya perkembangan teknologi informasi banyak memberikan kemudahan di bidang multimedia digital yang lebih unggul dibanding dengan multimedia konvensional. Informasi dalam bentuk digital memiliki sifat yang mudah untuk diubah dan dimodifikasi, sehingga dapat mengakibatkan permasalahan hak kepemilikan informasi itu sendiri. Keaslian informasi dalam berbagai bentuk dan media tidak lagi terjaga karena setiap orang dapat mengubah dan memodifikasinya untuk kemudian disebarkan kembali. Oleh karena itu, untuk menjaga hak kekayaan intelektual dari pemilik arsip multimedia yang bersangkutan dibutuhkan sebuah metode untuk menandai kepemilikan hak cipta atas sebuah citra digital. Salah satu teknik yang dapat digunakan untuk melindungi isi dan informasi yang terkandung dalam media adalah teknik watermarking. Referensi [5] menyebutkan tanda air (watermarking) dapat diartikan sebagai suatu teknik penyisipan dan atau penyembunyian informasi yang bersifat rahasia pada suatu data lainnya untuk "ditumpangi" (kadang disebut dengan host data), tetapi orang lain tidak menyadari adanya kehadiran data tambahan pada data host-nya (istilah host digunakan untuk data atau sinyal digital yang disisipi), sehingga seolah-olah tidak ada perbedaan berarti antara data host sebelum dan sesudah proses watermarking.

DWT membagi sebuah dimensi sinyal menjadi dua bagian yakni frekuensi tinggi dan frekuensi rendah, yang disebut dengan dekomposisi [11]. Keluaran dari highpass filter dan lowpass filter akan menghasilkan koefisien DWT, dengan menggunakan koefisien ini citra asli dapat direkontruksi. Proses rekontruksi ini disebut Inverse Discrete Wavelet Transform (IDWT). SVD merupakan teknik numerik yang digunakan untuk matrik diagonalisasi pada analisa numerik [3]. SVD menggeneralisasi dari dekomposisi eigen value untuk analisa matrik rectangular (dekomposisi eigen value didefinisikan hanya untuk matrik squared) dan juga dieksplorasi untuk image processing. Tujuan utama dari SVD adalah mendekomposisi sebuah matrik rectangular ke dalam tiga matrik sederhana (dua matrik orthogonal dan satu matrik diagonal). SVD telah banyak dipelajari dan digunakan untuk watermarking (terutama pada citra) [4]. Citra ber-watermark umumnya mendapat serangan (attack) dengan tujuan untuk menghilangkan watermark yang disisipkan di dalam citra digital tersebut. Serangan ini disebut sebagai serangan yang disengaja. Serangan yang tidak disengaja biasanya berhubungan dengan pengubahan citra digital, seperti berupa cropping, rotation, dilation, filterisasi, kompresi, dan lain-lain. Perbandingan antara citra asli dan citra ber-watermark menunjukkan ketahanan citra menghadapi serangan.

Pada penelitian [1], citra watermark disisipkan dengan menggunakan metode Discrete Wavelet Transform (DWT) dan menghasilkan citra ber-watermark yang tidak tahan terhadap attack atau memiliki ketahanan yang kurang. Kelemahan tersebut menjadi fokus perhatian pada penelitian ini. Simulasi algoritma watermarking yang dibuat dengan menggunakan Discrete Wavelet Transform (DWT) dan Singular Value Decomposition (SVD) merupakan perbaikan dan perluasan dari penelitian sebelumnya. Paper [12] memiliki kelemahan hanya disimulasikan pada citra grayscale saat menggunakan metode DWT-SVD. Dengan menggunakan metode yang sama penelitian [2] memiliki kekurangan, yakni algoritma penyisipan citra watermark tidak sesuai dengan konsep watermarking yang banyak dipelajari.

Berdasarkan uraian di atas, maka penulis mencoba untuk mengimplementasikan metode hybrid DWT-SVD pada image watermarking. Penelitian ini menggunakan citra host berwarna 
sehingga perlu dilakukan proses konversi citra RGB menjadi komponen $\mathrm{Y}, \mathrm{Cb}$, dan $\mathrm{Cr}$. Pada masing-masing komponen warna tersebut akan dilakukan proses penyisipan citra watermark dengan metode DWT-SVD dan diakhir penyisipan dilakukan proses konversi kembali citra RGB.

\section{METODE PENELITIAN}

\subsection{Discrete Wavelet Transform (DWT)}

Transformasi wavelet mulai diperkenalkan pada tahun 1980-an oleh Morlet dan Grossman sebagai fungsi matematis untuk merepresentasikan data atau fungsi sebagai alternatif transformasitransformasi matematika yang lahir sebelumnya untuk menangani masalah resolusi [8]. Transformasi ini memiliki dua seri dalam pengembangannya yaitu Continous Wavelet Transform (CWT) dan Discrete Wavelet Transform (DWT). Dasar dari DWT dimulai pada tahun 1976 dimana teknik untuk mendekomposisi sinyal waktu diskrit ditemukan [9]. Di dalam CWT, sinyal dianalisis menggunakan seperangkat fungsi dasar yang saling berhubungan dengan penskalaan dan transisi sederhana. Sedangkan di dalam DWT, penggambaran sebuah skala waktu sinyal digital didapatkan dengan menggunakan teknik filterisasi digital. Secara garis besar proses dalam teknik ini adalah dengan melewatkan sinyal yang akan dianalisis pada filter dengan frekuensi dan skala yang berbeda.

Sebuah sinyal harus dilewatkan dalam dua filterisasi DWT yaitu highpass filter dan lowpass filter agar frekuensi dari sinyal tersebut dapat dianalisis. Analisis sinyal dilakukan terhadap hasil filterisasi highpass filter dan lowpass filter dimana highpass filter digunakan untuk menganalisis frekuensi tinggi dan lowpass filter digunakan untuk menganalisis frekuensi rendah. Pembagian sinyal ini disebut sebagai dekomposisi. Secara teknis, citra dengan dua dimensi (baris dan kolom) dapat didekomposisi seperti Gambar 1. Dengan I adalah citra, $\mathrm{H}(\omega)$ adalah highpass filter, dan $\mathrm{G}(\omega)$ adalah lowpass filter.

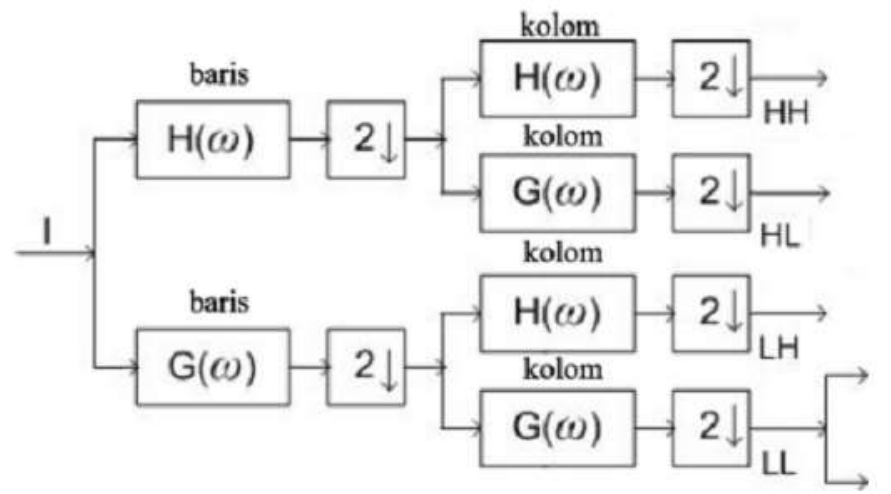

Gambar 1. Dekomposisi wavelet satu tingkat terhadap citra [10]

Dekomposisi pada citra menghasilkan informasi rentang frekuensi yang berbeda yaitu LL (low-low frequency), LH (low-high frequency), HL (high-low frquency), dan $\mathrm{HH}$ (high-high frequency), seperti ditunjukkan Gambar 2. Rentang frekuensi LL merupakan rentang taksiran penskalaan, sedangkan rentang frekuensi LH, HL, dan $\mathrm{HH}$ merupakan rentang frekuensi detil informasi [10].

\subsection{Singular Value Decomposition (SVD)}

Singular Value Decomposition (SVD) adalah teknik numerik yang digunakan untuk matrik diagonalisasi dalam analisis numerik. SVD merupakan algoritma yang dikembangkan untuk berbagai aplikasi. Setiap matrik sebuah citra $C$ didekomposisi menjadi tiga sub matrik $[u, s, v]$, seperti berikut ini : 
$C=U * S * V^{T}$

Dimana $U$ dan $V$ adalah matrik orthogonal sehingga $U^{*} U^{T}=I$ dan $V^{*} V^{T}=I$, dimana $I$ adalah matrik identitas dan $s$ adalah matrik diagonal. Nilai tersebut dikenal sebagai singular value dan matrik $U$ dan $V$ diketahui sebagai vector singular terkait [7]. Dekomposisi di atas disebut sebagai Singular Value Decomposition. Sebuah SVD, yang diterapkan pada matrik sebuah citra, memberikan singular value (matrik diagonal) yang mewakili luminance atau intensitas warna dari citra dimana matrik $U$ dan $V$ mewakili geometri dari citra. Secara ilmiah telah dibuktikan bahwa variasi kecil dalam singular value tidak mengubah persepsi visual dari citra [6].

Pendekatan rank $r$ dari sebuah citra $C(x, y)$ adalah matrik $C_{r}(x, y)=U_{r} S_{r} V_{r}^{T}$, dimana $S_{r}$ adalah sub matrik bagian kiri atas $(r x r), U_{r}$ terdiri dari kolom pertama $r$ dari $U$, dan $V_{r}^{T}$ adalah baris pertama $r$ dari $V_{r}$. Dekomposisi SVD sangat menarik karena $U_{r} S_{r} V_{r}^{T}$ menyediakan pendekatan rank $r$ terbaik untuk $X$ dalam arti kemasan energi maksimum dari $X$ [4].

$C(x, y)=U S V^{r}$

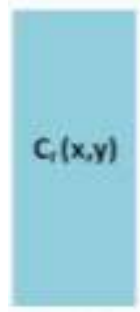

$\mathrm{N} \times \mathrm{M}$

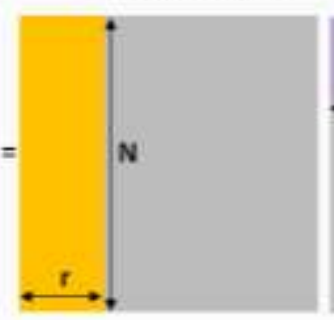

$\mathrm{N} \times \mathrm{N}$

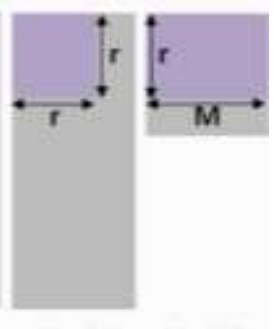

$\mathrm{N} \times \mathrm{M} \quad \mathrm{M} \times \mathrm{M}$

Gambar 2. Operasi SVD pada citra $C$ [4]

\section{DESAIN SISTEM}

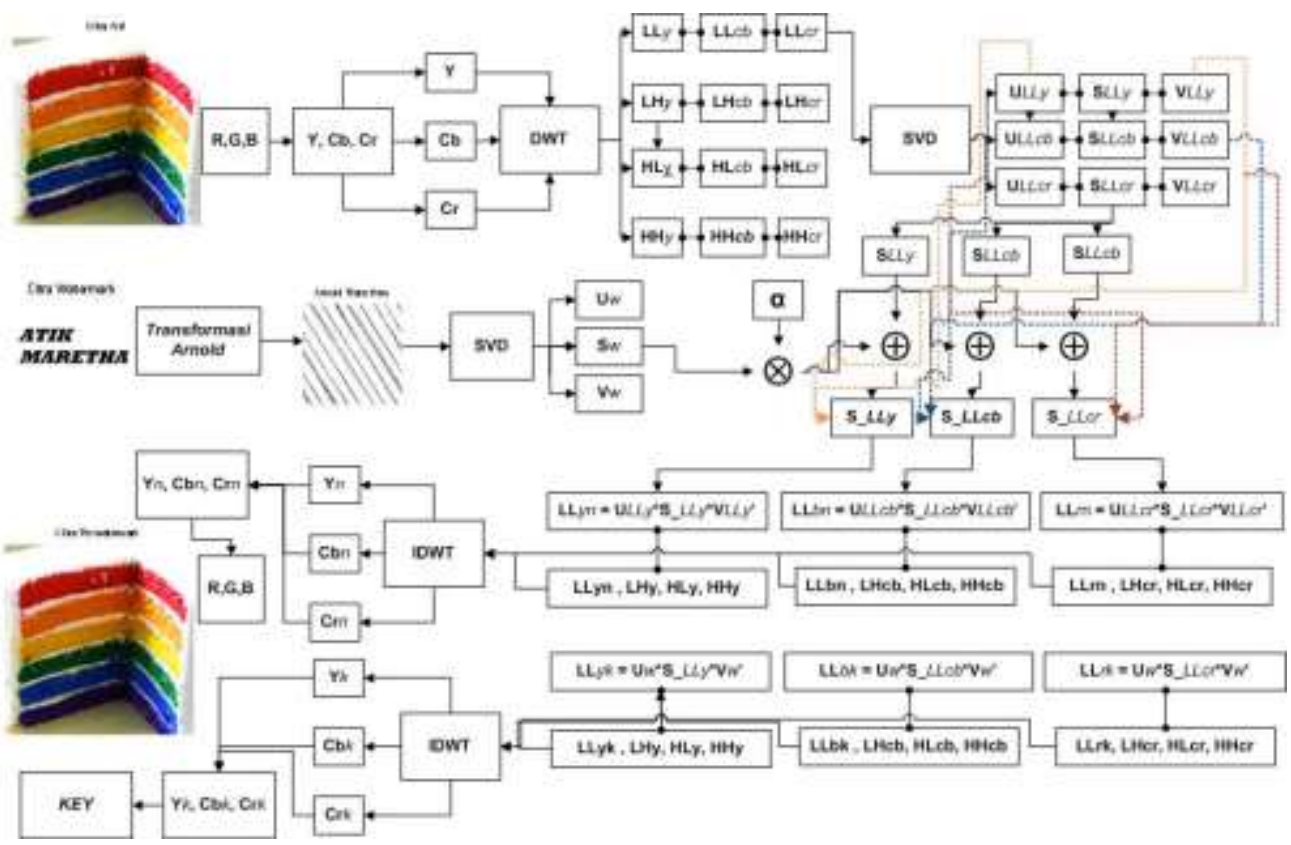

Gambar 3. Proses penyisipan citra watermark ke dalam citra host dengan metode DWT-SVD 


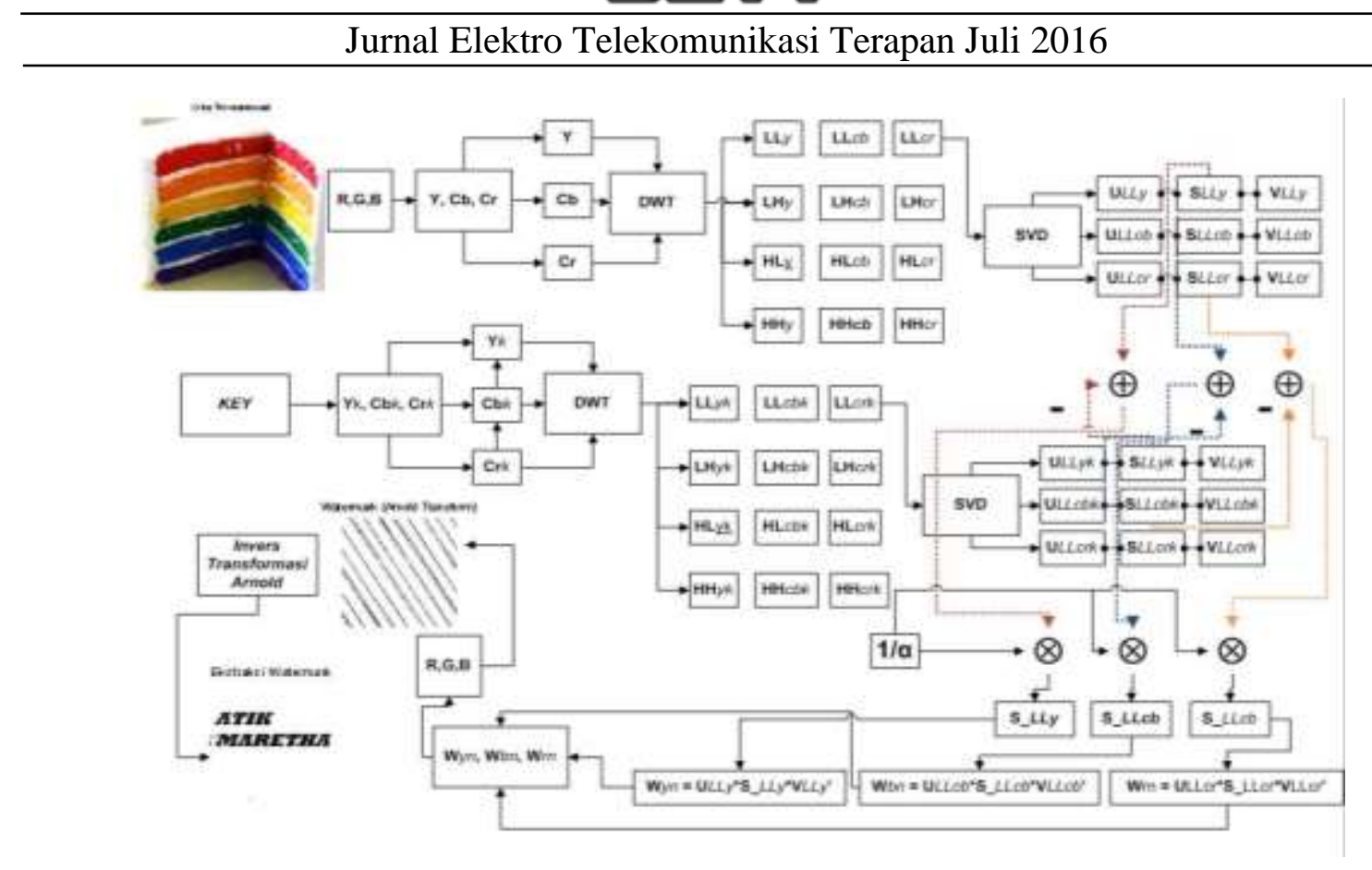

Gambar 4. Proses ekstraksi citra ber-watermark dengan metode DWT-SVD

\section{HASIL DAN DISKUSI}

Simulasi menggunakan Matlab 7.9.0 (R2009b) dengan menggunakan beberapa citra host berwarna berukuran $256 \times 256$ pixel dan sebuah citra watermark berukuran $128 \times 128$, pixel seperti ditampilkan pada Tabel 1.

\begin{tabular}{|c|c|c|c|}
\hline \multicolumn{3}{|c|}{ Citra host } \\
\hline lena.tif & taylor.jpg & rainbow.bmp & Hawaii.jpg \\
\hline & & & \\
\hline
\end{tabular}

(a)

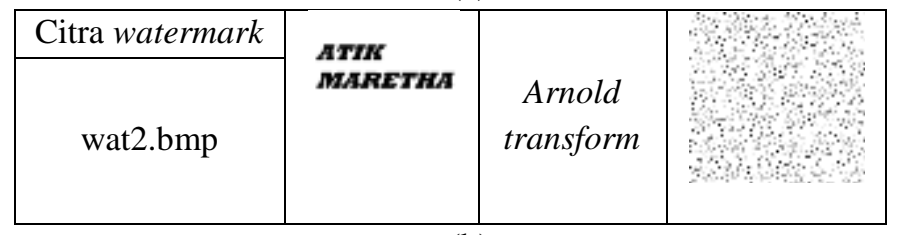

(b)

Pada simulasi yang telah dilakukan, citra watermark disisipkan pada citra host dengan menggunakan dua metode yaitu metode discrete wavelet transform (DWT) saja dan metode hybrid yaitu discrete wavelet transform (DWT) dengan singular value decomposition (SVD). Hasil simulasi kedua metode tersebut menunjukkan perbedaan pada beberapa hal, seperti pada PSNR dan ketahanan terhadap attack. Hasil simulasi menggunakan metode DWT, dimana hasil penyisipan watermark pada citra host dengan $\alpha=0.01$ yaitu watermarked image dengan PSNR dalam dB. Nilai PSNR dari beberapa watermarked image, penyisipan watermark terhadap citra host taylor.jpg memiliki PSNR paling tinggi yaitu $94.2046 \mathrm{~dB}$. Dalam simulasi ini masih mengabaikan attack. Proses ekstraksi watermark menggunakan nilai $\alpha$ yang sama. Sehingga dari hasil simulasi 
menunjukkan semakin tinggi PSNR suatu watermarked image akan menyebabkan hasil ekstraksi watermark semakin mendekati citra watermark seperti pada Tabel 2.

\begin{tabular}{|c|c|c|}
\hline $\begin{array}{c}\text { Watermarked } \\
\text { image }\end{array}$ & PSNR (dB) & $\begin{array}{l}\text { Ekstraksi } \\
\text { watermark }\end{array}$ \\
\hline & 94.2046 & $\begin{array}{l}\text { ATIR } \\
\text { MARETHA }\end{array}$ \\
\hline & 91.1306 & $\begin{array}{l}\text { ArH } \\
\text { MARETHA } \\
\end{array}$ \\
\hline & 83.3291 & ${ }_{\text {MThRETHA }}$ \\
\hline 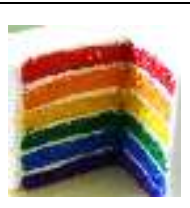 & 81.8171 & ATri \\
\hline
\end{tabular}

Tabel 3. PSNR dan Hasil Ekstraksi Watermark DWT dengan Attack

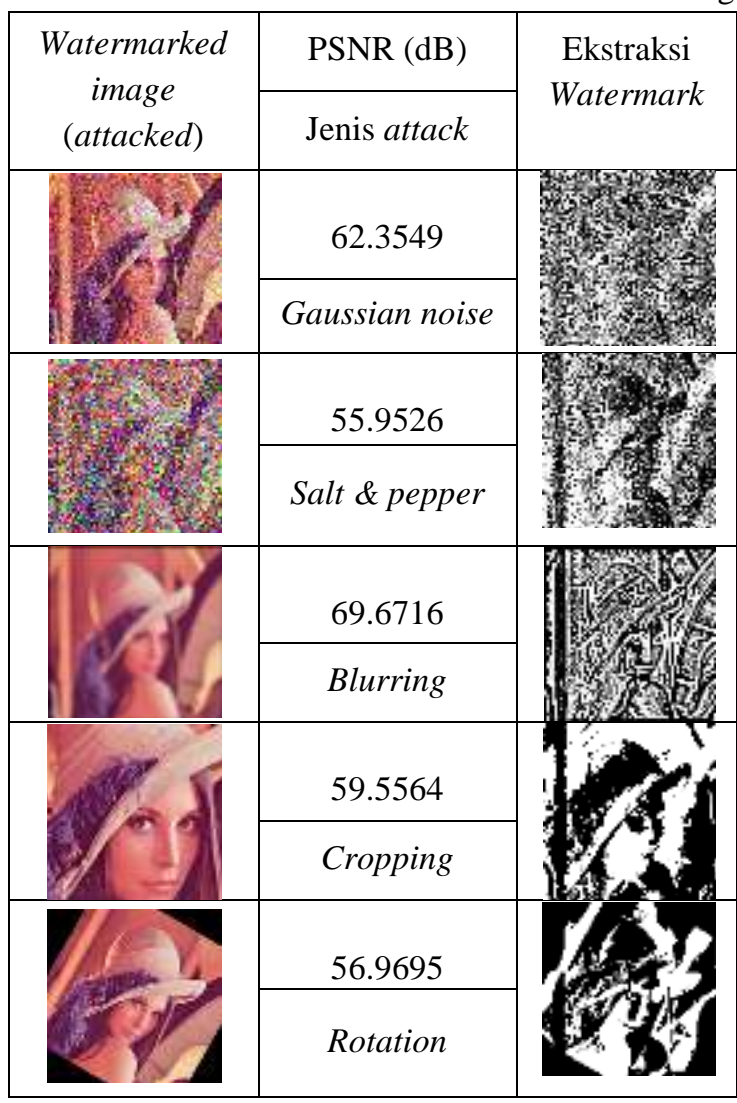


Tabel 3 merupakan hasil simulasi metode DWT untuk proses penyisipan dan ekstraksi watermark, dimana setelah proses penyisipan watermark pada citra host, watermarked image tersebut diberi attack. Semua watermarked image yang diberi attack seperti ditunjukkan pada Tabel 3, tidak dapat diekstraksi watermark-nya. Sehingga selanjutnya metode hybrid DWT-SVD digunakan untuk menangani attack, agar watermark tetap dapat diekstraksi.

Proses penyisipan watermark dengan Arnold transform menghasilkan PSNR lebih tinggi dibandingkan tanpa Arnold transform. Hal tersebut seperti ditunjukkan pada watermarked image taylor.jpg, dengan Arnold transform PSNR $=85.7959 \mathrm{~dB}$, dan tanpa Arnold transform $\mathrm{PSNR}=$ 85.3901 dB. Proses penyisipan watermark dengan Arnold transform membuat hasil ekstraksi berbeda dengan proses penyisipan watermark tanpa Arnold transform. Penggunaan Arnold transform membuat semakin rendah PSNR maka semakin jelas watermark-nya, sedangkan pada saat tidak menggunakan Arnold transform akan terjadi sebaliknya.

Citra lena.tif dan taylor.jpg digunakan untuk mengamati pengaruh besarnya $\alpha$ terhadap hasil ekstraksi watermark. Tabel 4 dan 5 menunjukkan perubahan $\alpha$ dari 0.01 hingga 0.9 . Perubahan $\alpha$ dalam simulasi dilakukan saat proses ekstraksi watermark. Sedangkan perubahan $\alpha$ tidak dilakukan dalam proses penyisipan watermark, dimana $\alpha$ yang digunakan tetap 0.01 agar menghasilkan watermarked image yang serupa dengan citra host.

Pada Tabel 4 menunjukkan watermarked image lena.tif memiliki similarity factor (SF) lebih tinggi dibanding watermarked image taylor.jpg. Hal tersebut dikarenakan PSNR watermarked image taylor.jpg lebih tinggi daripada watermarked image lena.tif, karena seperti yang dijelaskan sebelumnya bahwa semakin rendah PSNR maka semakin jelas watermark-nya. Perubahan nilai $\alpha$ berpengaruh terhadap seberapa jelas hasil ekstraksi watermark, dimana semakin tinggi nilai $\alpha$ dengan PSNR yang tetap, maka SF akan semakin mendekati satu. Seperti hasil simulasi yang ditunjukkan pada Tabel 4, begitu juga yang terjadi pada hasil simulasi di Tabel 5. Perbedaannya terdapat pada penggunaan Arnold transform atau tidak. Bila diperhatikan pada Tabel 4 dan 5, penggunaan Arnold transform tidak selalu memperbaiki hasil ekstraksi watermark, tetapi dengan menggunakan Arnold transform nilai SF-nya cenderung lebih tinggi atau lebih mendekati satu.

Tabel 4. Pengaruh $\alpha$ terhadap Hasil Ekstraksi Watermark DWT-SVD tanpa Arnold Transform

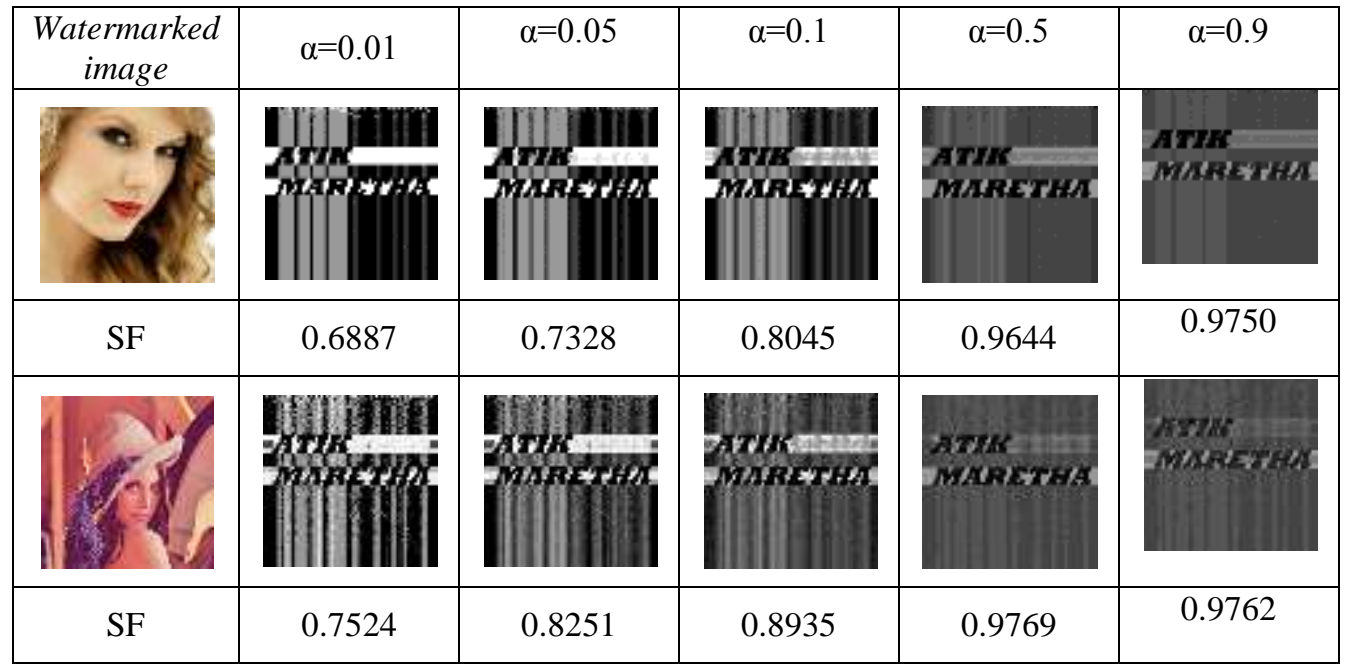

Penggunaan nilai a saat proses penyisipan watermark ke dalam citra host sangat berpengaruh terhadap citra ter-watermark dan tentu saja terhadap nilai PSNR. Perbandingan hasil 
penggunaan $\alpha$ saat proses penyisipan dengan menggunakan metode DWT menunjukkan bahwa semakin besar nilai $\alpha$ maka watermark yang disisipkan akan semakin terlihat seiring dengan tingkat kecerahan citra host yang semakin rendah. Berdasarkan pengamatan, watermark mulai terlihat saat menggunakan nilai a sama dengan 0.1, namun tidak tampak jelas tergantung citra host yang digunakan. Empat citra yang digunakan diketahui PSNR paling tinggi dihasilkan oleh citra taylor dengan nilai 94.2046 dB dan paling rendah dihasilkan oleh citra Hawaii dengan nilai 56.1324.

Tabel 5. Pengaruh $\alpha$ terhadap Hasil Ekstraksi Watermark DWT-SVD dengan Arnold Transform

\begin{tabular}{|c|c|c|c|c|c|}
\hline $\begin{array}{c}\text { Watermarked } \\
\text { image }\end{array}$ & $\alpha=0.01$ & $\alpha=0.05$ & $\alpha=0.1$ & $\alpha=0.5$ & $\alpha=0.9$ \\
\hline & 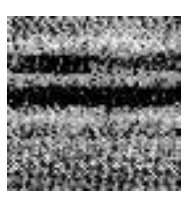 & 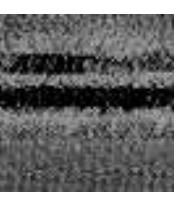 & Mowr. & & \\
\hline SF & 0.8485 & 0.9225 & 0.9590 & 0.9743 & 0.9668 \\
\hline & $\begin{array}{l}\text { Arni } \\
\text { maresran }\end{array}$ & $\begin{array}{l}\text { ATrus } \\
\text { Motnexysh }\end{array}$ & 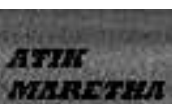 & $\begin{array}{l}\text { gTHK } \\
\text { VARETHA }\end{array}$ & 12 \\
\hline $\mathrm{SF}$ & 0.9010 & 0.9552 & 0.9822 & 0.9749 & 0.9667 \\
\hline
\end{tabular}

Selain itu perbandingan hasil penggunaan $\alpha$ saat proses penyisipan dengan menggunakan metode DWT-SVD menunjukkan bahwa besar nilai $\alpha$ yang digunakan saat penyisipan watermark berpengaruh terhadap citra hasil proses watermarking. Semakin besar nilai $\alpha$ yang digunakan maka citra ter-watermark semakin cenderung mengalami perubahan menjadi citra dengan unsur warna merah muda. Berdasarkan data penelitian, citra ter-watermark mulai terlihat unsur warna merah muda ketika $\alpha$ sama dengan 0.1 dan seterusnya. Selain itu, semakin besar nilai $\alpha$ yang digunakan pada saat penyisipan watermark maka semakin rendah nilai PSNR yang diperoleh. Grafik pada Gambar 5 adalah perbandingan antara $\alpha$ dan PSNR dengan menggunakan metode DWT dan DWTSVD untuk citra tylor.jpg.

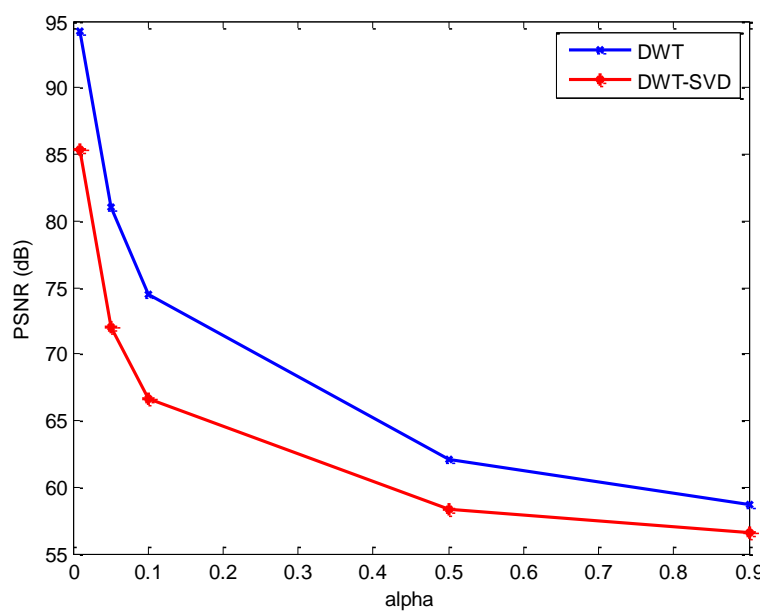

Gambar 5. Pengaruh penggunaan $\alpha$ saat penyisipan watermark terhadap nilai PNSR 
Hasil simulasi yang ditunjukkan pada Tabel 6 merupakan hasil ekstraksi dari watermarked image yang diberi attack. Attack yang digunakan adalah Gaussian noise, rotation, dan blurring. Bila diamati pada Tabel 6 terdapat perbedaan bila menggunakan Arnold transform dan tanpa menggunakan Arnold transform. Pada simulasi penambahan Gaussian noise dan blurring menunjukkan bahwa penggunaan Arnold transform dapat memberikan hasil ekstraksi lebih jelas. Hal sebaliknya terjadi pada attack berupa rotation yang menunjukkan tanpa Arnold transform dapat memberikan hasil ekstraksi lebih jelas. Penambahan attack tidak selalu menunjukkan nilai SF tinggi yang bisa menampilkan hasil ekstraksi lebih jelas atau mendekati citra watermark (Tabel $1 b)$.

Hal tersebut seperti simulasi penambahan attack blurring, dimana saat $\alpha=0.01$, dengan Arnold transform menunjukkan $\mathrm{SF}=0.2016$ memiliki hasil ekstraksi lebih bagus, dibandingkan tanpa Arnold transform yang menunjukkan SF lebih tinggi yaitu 0.6038. Ini dikarenakan saat SF $=0.2016$, warnanya berlawanan dengan citra watermark seperti pada Tabel 1b. Berdasarkan hasil simulasi yang ditunjukkan pada Tabel 6, maka dengan menggunakan metode hybrid DWT-SVD ini, watermarked image lebih tahan terhadap attack. Sehingga walaupun diberi attack, watermarked image tetap dapat diekstraksi untuk mengetahui identitas dari citra.

\section{KESIMPULAN}

Berdasarkan simulasi yang telah dilakukan maka dapat disimpulkan beberapa hal, yaitu :

1. Penyisipan watermark terhadap citra host taylor.jpg memiliki PSNR paling tinggi yaitu 94.2046 dB saat proses ekstraksi watermark menggunakan nilai $\alpha$ yang sama dan masih mengabaikan attack.

2. Metode DWT-SVD lebih tahan terhadap attack dibandingkan dengan metode DWT.

3. Proses penyisipan watermark dengan Arnold transform menghasilkan PSNR lebih tinggi dibandingkan tanpa Arnold transform, dimana dengan Arnold transform PSNR $=85.7959 \mathrm{~dB}$, dan tanpa Arnold transform PSNR = 85.3901 dB.

4. Semakin rendah PSNR maka semakin tinggi nilai similarity factor (SF) dan semakin jelas watermark-nya.

5. semakin besar nilai $\alpha$ yang digunakan pada saat penyisipan watermark maka semakin rendah nilai PSNR yang diperoleh.

6. Saat nilai PSNR tetap, semakin tinggi nilai $\alpha$ maka SF akan semakin mendekati satu.

7. Penggunaan Arnold transform tidak selalu memperbaiki hasil ekstraksi watermark, tetapi dengan menggunakan Arnold transform nilai SF-nya cenderung lebih tinggi atau lebih mendekati satu.

8. Penggunaan Arnold transform dapat mengenkripsi watermark sehingga lebih tahan terhadap attack dan watermark dapat diekstraksi kembali.

\section{Daftar Pustaka:}

[1] Chaturvedi, Navnidhi et al. 2012. Analysis of Image Watermarking by DWT and Performance Under Attacks. International Journal of Computer Technology and Electronics Engineering (IJCTEE), Vol.2, Issue.3, June.

[2] Kamble, Sushila et al. 2012. DWT-SVD Based Robust Image Watermarking Using Arnold Map. International Journal of Information Technology and Knowledge Management, Vol.5, No.1, pg 101-105, January-June. 
[3] Kelkar, Yashovardhan et al. 2013. Analysis of Robustness of Hybrid Digital Image Watermarking Technique under Various Attacks. IJCSMC, Vol.2, Issue.3, pg.137 - 143. March.

[4] Majumder Swanirbhar et al. 2008. A Hybrid SVD and Wavelet based Watermarking. $2^{\text {nd }}$ National Conference Mathematical Techniques : Emerging Paradigms for Electronics and IT Industries. September.

[5] Munir, Rinaldi. 2006. Diktat Kuliah IF5054 Kriptografi. Bandung : Institut Teknologi Bandung.

[6] Saxena, Vikas et al. Towards Increasing The Robustness of Image Watermarking against JPEG Compression.

[7] Seitz J. Digital watermarking For Digital Media. Information Science Publishing, United States of America.

[8] Siregar, Isma Fahdiani. 2008. Implementasi Steganografi Pada Video Jenis Avi Menggunakan Transformasi Wavelet Diskrit. Bandung : Institut Teknologi Telkom.

[9] Sripathi, Deepika. 2003. Efficient Implementations of Discrete Wavelet Transform using FPGAs. Florida State University.

[10] Technical Advisory Service for Images. 2005. The Digital Image. http://www.tasi.ac.uk.

[11] Terzija, Natasa. 2006. Robust Digital Image Watermarking Algorithms for Copyright Protection. Universität Duisburg -Essen.

[12] Zhou, Yaxun et al. 2012. A Robust Digital Image Multi-watermarking Scheme in the DWT Domain. International Conference on Systems and Informatics.

\section{LAMPIRAN}

Tabel 6. Hasil Ekstraksi Watermark DWT-SVD dengan Attack

\begin{tabular}{|c|c|c|c|c|c|}
\hline $\begin{array}{c}\text { Watermarked } \\
\text { image }\end{array}$ & $\alpha=0.01$ & $\alpha=0.05$ & $\alpha=0.1$ & $\alpha=0.5$ & $\alpha=0.9$ \\
\hline \multicolumn{6}{|c|}{ Dengan Arnold transform, Gaussian noise, mean $=0.5$, varian $=1$} \\
\hline 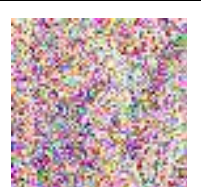 & 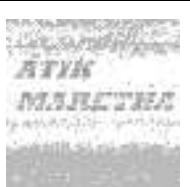 & 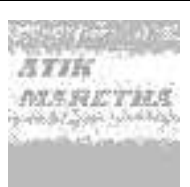 & 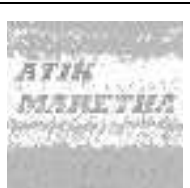 & 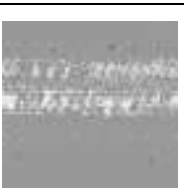 & \\
\hline SF & 0.9571 & 0.9556 & 0.9547 & 0.9457 & 0.9447 \\
\hline \multicolumn{6}{|c|}{ Tanpa Arnold transform, Gaussian noise, mean $=0.5$, varian $=1$} \\
\hline 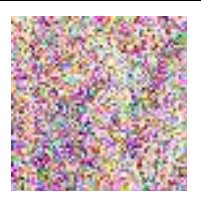 & 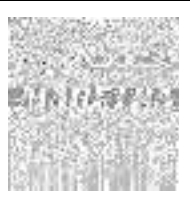 & 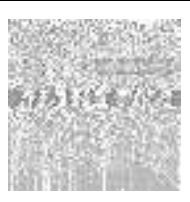 & mostis & & Whetersogh: \\
\hline SF & 0.9326 & 0.9306 & 0.9309 & 0.9521 & 0.9630 \\
\hline \multicolumn{6}{|c|}{ Dengan Arnold transform, Rotation $30^{\circ}$, PSNR $=56.9501 \mathrm{~dB}$} \\
\hline
\end{tabular}




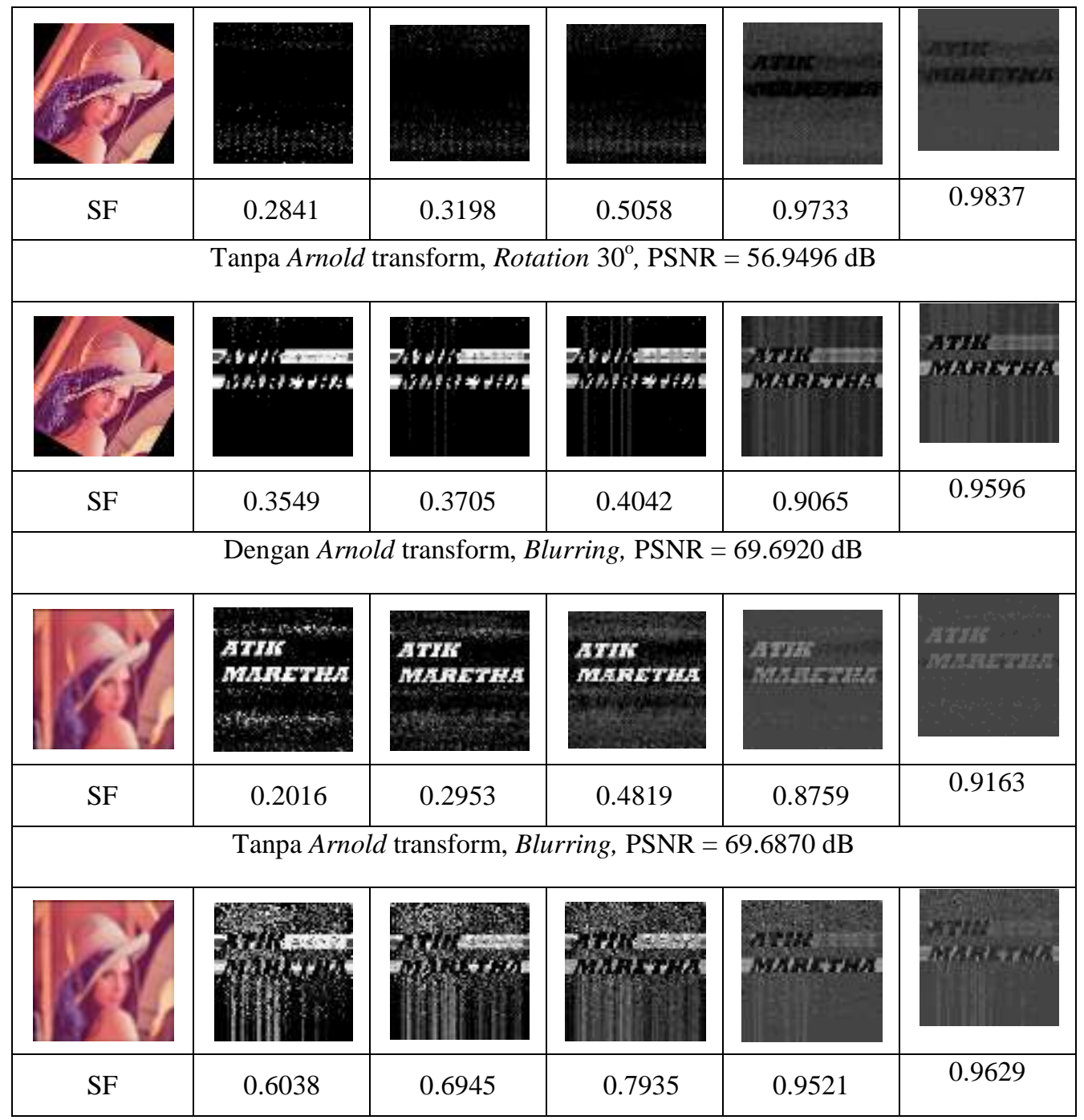

